\title{
A Pushed Descending Aorta due to Hiatal Hernia
}

\author{
Cetin Gecmen, MD ${ }^{1}$ Muzaffer Kahyaoglu, MD ${ }^{1}$ Arzu Kalayci, MD ${ }^{1}$ Ender Ozgun Cakmak, MD \\ Ozkan Candan, MD ${ }^{1}$ Ahmet Guner, MD ${ }^{1}$ Ibrahim Akin Izgi, MD ${ }^{1}$ Cevat Kirma, MD ${ }^{1}$
}

${ }^{1}$ Department of Cardiology, Kartal Kosuyolu Heart and Research Hospital, Istanbul, Turkey

AORTA 2018;6:107-108.
Address for correspondence Cetin Gecmen, MD, Department of Cardiology, Kartal Kosuyolu Heart and Research Hospital, 34846, Kartal, Istanbul, Turkey (e-mail: koronerr@hotmail.com).

\section{Abstract \\ Keywords \\ - descending aorta \\ - aortic displacement \\ - hiatal hernia}

A 91-year-old female patient was admitted to hospital for evaluation of transcatheter aortic valve implantation. A chest radiography showed a hiatal hernia, and the stomach and duodenum appeared in the thoracic cavity. The descending aorta was pushed by the stomach and duodenum.
A 91-year-old female patient was admitted to hospital for evaluation of transcatheter aortic valve implantation. A chest radiography showed a hiatal hernia, and the stomach and duodenum appeared in the thoracic cavity (-Fig. 1A). The patient had severe aortic stenosis, and a contrastenhanced thoracoabdominal computed tomography (CT) was performed to evaluate vascular structures. A contrast-enhanced CT scan of the chest in the coronal plane revealed normal diameter and non-tortuous ascending aorta (-Fig. 1B). The descending aorta was pushed by the

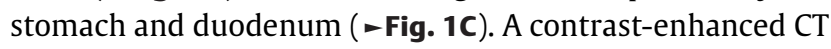
scan of the chest in the sagittal plane showed the pushed descending aorta ( - Fig. 1D). A contrast-enhanced CT scan of the chest in axial plane showed the descending aorta on the left side of the vertebra (-Fig. 1E). The abdominal aorta travels on the left side of the vertebra (-Fig. 1F). A successful intervention was done, and the patient was discharged from the hospital. received

June 1, 2017

accepted after revision

November 5, 2018
DOI https://doi.org/

10.1055/s-0039-1679910.

ISSN 2325-4637.
Copyright $\odot 2018$ by Thieme Medical Publishers, Inc., 333 Seventh Avenue, New York, NY 10001, USA. Tel: +1(212) 584-4662.
License terms

() (1) 


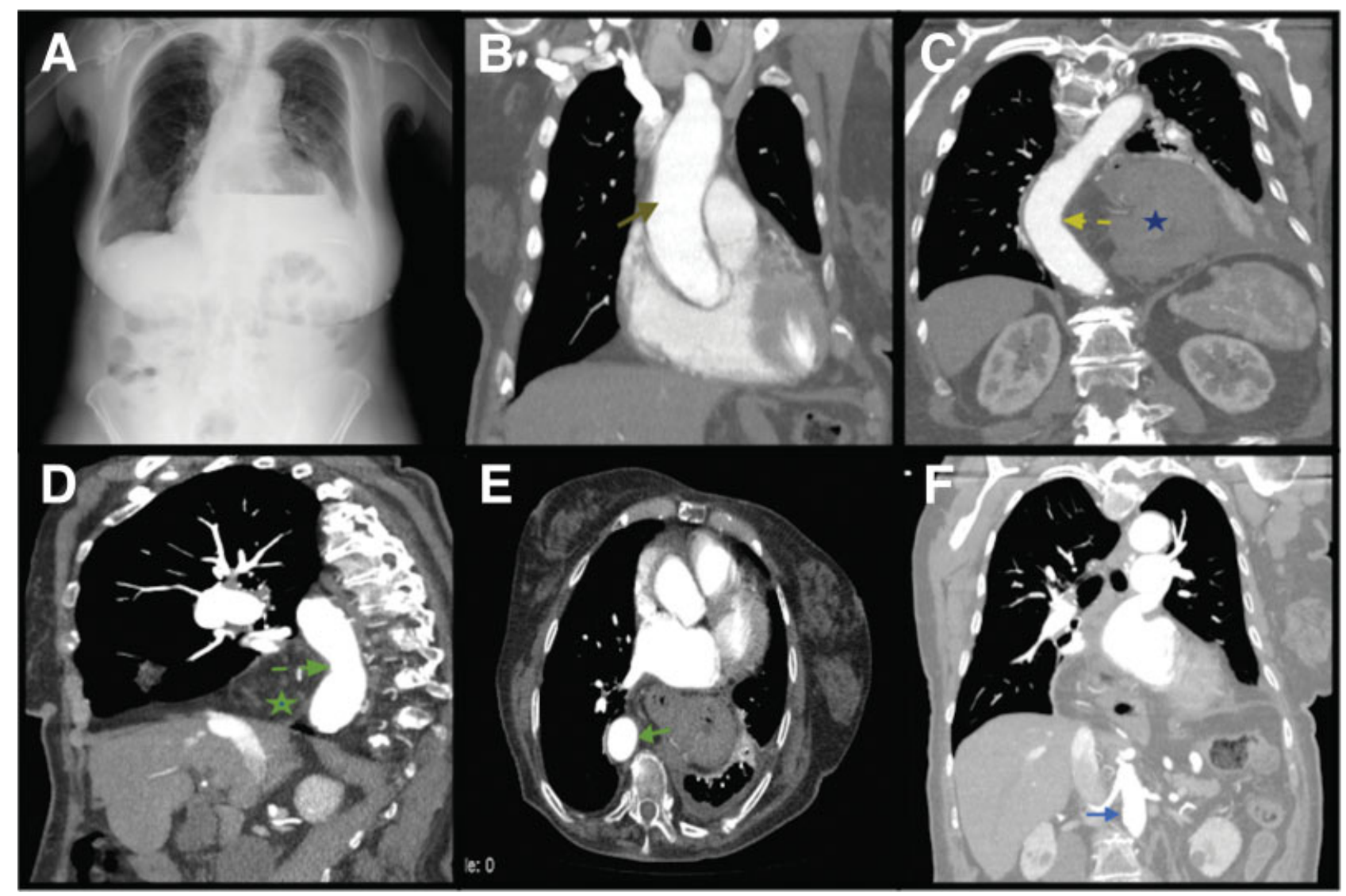

Fig. 1 (A) A chest radiography showing hiatal hernia and stomach in the thoracic cavity. (B) A contrast-enhanced computed tomography (CT) scan of the chest in coronal plane showing non-tortuous ascending aorta. (C) A contrast-enhanced CT scan of the chest in coronal plane showing the pushed descending aorta. (D) A contrast-enhanced CT scan of the chest in sagittal plane showing the pushed descending aorta. (E) A contrast-enhanced CT scan of the chest in axial plane showing the descending aorta on the left side of the vertebra. (F) Abdominal aorta travels on the left side of the vertebra.

\section{Funding}

None.

\section{Conflict of Interest}

The authors declare no conflict of interest related to this article.

\section{Acknowledgements}

None. 